\title{
Improvements to Seismic Monitoring of the European Arctic \\ Using Three-Component Array Processing at SPITS
}

S. J. Gibbons, ${ }^{1}$ J. Schweitzer, ${ }^{1}$ F. Ringdal, ${ }^{1}$ T. Kværna, ${ }^{1}$ S. Mykkeltveit, ${ }^{1}$ and B. Paulsen ${ }^{1}$

S. J. Gibbons, NORSAR, P.O. Box 53, 2027 Kjeller, Norway. (steven.gibbons@norsar.no)

J. Schweitzer, NORSAR, P.O. Box 53, 2027 Kjeller, Norway. (johannes@norsar.no)

F. Ringdal, NORSAR, P.O. Box 53, 2027 Kjeller, Norway. (frode@norsar.no)

T. Kværna, NORSAR, P.O. Box 53, 2027 Kjeller, Norway. (tormod@norsar.no)

S. Mykkeltveit, NORSAR, P.O. Box 53, 2027 Kjeller, Norway. (svein@norsar.no)

B. Paulsen, NORSAR, P.O. Box 53, 2027 Kjeller, Norway. (berit@norsar.no)

${ }^{1}$ NORSAR, P.O. Box 53, 2027 Kjeller,

Norway.

D R A F T

November 9, 2017, 8:39pm

D R A F T 
The detectability of low magnitude seismic events in the European Arctic is determined primarily by the small-aperture IMS arrays ARCES and SPITS. In August 2004, the SPITS array was upgraded to a broadband array with an increase in the sampling rate from 40 to $80 \mathrm{~Hz}$. Most importantly however for the detection and location of small magnitude seismic events was the deployment of three-component instruments at 6 of the 9 sites. Detection and correct classification of secondary phases are of paramount importance for events observed by only a small number of stations at regional distances and, in the absence of the strong Lg phases typically observed for continental propagation paths, multiple three-component stations were deemed necessary to exploit the higher S-phase amplitudes anticipated on the horizontal sensors. We demonstrate improved SNR for S phases on horizontal beams for several events close to Novaya Zemlya. Horizontal component f$\mathrm{k}$ analysis improves direction estimates and phase classification for low SNR signals. We demonstrate secondary phases which are misidentified by verticalonly f-k analysis but which are correctly classified by 3-C array processing. A significant problem with array processing at SPITS is the overlap in slowness space of regional $\mathrm{P}$ and $\mathrm{S}$ phases. Phase identification is improved greatly by comparing the coherence between vertical traces with the coherence between horizontal traces. Considerations in the routine array-processing of SPITS data are reviewed, including the need for elevation-corrections in slowness 
estimation and the need to take into account azimuth-dependent variation of apparent velocity estimates for regional phases. 


\section{Introduction}

The International Monitoring System (IMS) for the verification of compliance with the Comprehensive Nuclear Test-Ban-Treaty (CTBT) includes a global network of seismic array and 3-component (3-C) stations deployed in order to detect seismic disturbances which could indicate violations of this treaty. Two IMS arrays, ARCES (designated station PS28) and SPITS (designated station AS72), are located within the European Arctic (see Fig. 1). These stations predate the signing of the CTBT and were deployed to monitor seismicity in the region and to provide data for the development of processing schemes for a network of small-aperture arrays [Mykkeltveit et al., 1990]. The first data from ARCES came in 1987 and the final three nuclear explosions at the northern test-site on Novaya Zemlya (07-05-1988, 04-12-1988 and 24-10-1990) were recorded by this array [see Khalturin et al., 2005, for a comprehensive review of Soviet nuclear testing at Novaya Zemlya]. The SPITS array started providing seismic data in 1992, after the start of the testing moratorium, but has been of crucial importance in the detection and location of several small seismic events on or close to Novaya Zemlya since then [e.g. Ringdal, 1997]. Kvarna et al. [2002] describe how processing parameters at ARCES, SPITS, and the other Nordic regional seismic arrays, are tuned to provide an optimal detection capability and Seismic Threshold Monitoring for the region surrounding the Novaya Zemlya testing area.

Fig. 1 displays the locations of the SPITS and ARCES arrays, together with the IRIS 3-C stations KBS (Kings Bay, Svalbard) and KEV (Kevo, Finland), in relation to the seismicity of the European Arctic between 1998 and 2008. (A small number of seismic events prior to this period in the vicinity of Novaya Zemlya are also displayed.) The 
Spitsbergen archipelago and the diverging plate boundary to the west [see Engen et al., 2003] are by far the most seismically active areas in the region. To the south, on mainland Fennoscandia, the seismicity on the coastline is mostly natural whereas the majority of the symbols in northern Sweden and on the Kola Peninsula are related to large-scale mining activity. The large cluster of symbols in the Barents Sea to the northeast of the Kola Peninsula is related to activity in the aftermath of the Kursk submarine disaster on August 12, 2000. The eastern Barents Sea, including Novaya Zemlya, is relatively aseismic. Fig. 1 and tables 1 and 2 provide a list of detected seismic events in the vicinity of Novaya Zemlya since the deployment of the SPITS array in 1992. Earlier events, for example the magnitude 4.7 earthquake to the east of the northern test site on August 1, 1986 [Marshall et al., 1989], predate both the ARCES and SPITS arrays and are not considered in this paper. Events of magnitude 3.5 and above are likely to be detected in addition by the sensitive regional networks and arrays in Fennoscandia and it is highly unlikely that an event of this size has escaped detection within this period. The detection threshold at lower magnitudes than this is almost entirely determined by the ARCES and SPITS array stations and outages, excessive noise, or interfering signals, at either or both of these stations, will result in a decreased monitoring capability for the region.

Fig. 2 displays SPITS waveforms for the events listed in Table 1 (i.e. all the events known to have occurred close to Novaya Zemlya that were recorded on the short period array, prior to the upgrade in 2004). All seismograms displayed are beams of the vertical component traces steered using time-delays chosen to optimize the beam gain for either $\mathrm{P}$ or $\mathrm{S}$ arrivals. For each one of the events, only the Pn and Sn phases [see Storchak 
et al., 2003] are observed clearly; there is little or no evidence of the crustal Pg phase. As observed by Baumgardt [2001] for propagation paths across the Barents Sea from Novaya Zemlya to Scandinavia, the Lg phase is blocked. On continental propagation paths, Lg often dominates the vertical seismograms and can act as a surrogate for the frequently weak Sn phase, despite the challenges involved in applying Lg-onset time estimates to event location. In the absence of Lg, we only have the rather emergent and low signal-tonoise ratio (SNR) Sn phases with which to constrain the epicentral distances to the few observing stations.

The automatic detection of Sn at one or more of the stations displayed in Fig. 1 may be crucial for the event to be identified at all. Phases are usually detected and classified on a single small aperture array by a process of beamforming, detection on the beams by reporting significant values of the ratio between the short term average (STA) and the long term average (LTA), and then estimation of the best-fit slowness vector using f-k analysis [e.g. Mykkeltveit and Bungum, 1984]. Phase detection lists from different stations are then processed by a regional or global association algorithm [e.g. Ringdal and Kvarna, 1989; Kvarna et al., 1999] to generate event hypotheses based on various combinations of detected phases. Any association algorithm requires bounds within which phase arrival times, slowness and azimuth estimates must fall if they are to be included in a given event hypothesis. If the bounds are too narrow, real events may be missed due to bias or uncertainty in the phase parameter estimates, or inadequacies in the velocity models. If the bounds are too wide, the number of false alarms and spurious events may overwhelm the system and valid events may even be lost due to incorrect phase 
associations. The variability of parameter estimates for different phases must be assessed systematically to find the most stable characteristics of waveforms from a given source region, such that the association criteria can be set both to minimize the likelihood of missed events and to limit the false-alarm rate. In the absence of some additional, sitespecific, monitoring procedure, an event with only one detected phase is almost always missed since we have at best a direction estimate without a distance. Events with only two associated regional P-phases may provide a reasonable event hypothesis, depending upon the relative locations of the two arrays and the event hypocenter. This is however not really the case for the large region surrounding Novaya Zemlya with respect to the SPITS and ARCES arrays given the large azimuthal gap, the lack of calibration data concerning slowness and azimuth deviations [c.f. Schweitzer, 2001], and the wide range of epicentral distances of interest. The secondary phases contribute to providing these necessary constraints and it is imperative that they are detected with as accurate an arrival time estimate as possible, and associated with acceptably constrained parameters which correctly identify the phase.

Seismic arrays traditionally have consisted only of vertical sensors, usually together with a single 3-C seismometer or, at best, with 3-C instruments at a small number of sites. (The earliest seismic arrays were only intended to detect and identify teleseismic P-arrivals and these are expected to generate the greatest amplitudes on the vertical components.) The initial SPITS array consisted of 9 short-period vertical sensors and a single 3-C broadband seismometer at the site SPB4. The importance of the horizontal components for the observation of events of interest is demonstrated in Fig. 3 which shows 
SPITS waveforms for the August 16, 1997, Kara Sea event. The uppermost two traces show beams of the short-period traces steered to optimize detection of the Pn and Sn phases. The lowermost trace displays the horizontal components of the 3 -C instrument rotated perpendicular to the great circle backazimuth and it is evident that this transverse rotation at a single site provides a far greater SNR for the Sn phase than the beam of vertical traces. While both the radial and transverse horizontal components are likely to display a higher amplitude for the S-phases, the transverse component is less likely to be susceptible to interference from the P-coda, S-to-P and P-to-S conversions arriving prior to the direct $\mathrm{S}$ phase. 3-C instruments at more sites may allow additional improvement to the SNR through beamforming and for parameter estimation using $\mathrm{f}-\mathrm{k}$ analysis on the horizontal components. An additional motivation for the deployment of multiple 3-C stations is redundancy; the single 3-C instrument was inoperational at the times of other events in the Novaya Zemlya region for which we have no recordings of horizontal ground motion at SPITS. This situation could have been avoided given a 3-C (sub)array.

Tuning studies for optimizing phase detection and classification [Schweitzer, 1998; Kvarna et al., 1999] identified additional challenges in array processing with SPITS. These include the presence of huge numbers of high amplitude and high frequency signals from local events, and persistant bias in apparent velocity measurements which made phase identification and association difficult. A number of possible modifications to the array, designed to mitigate these problems and improve the monitoring capability, were discussed by Schweitzer and Kvarna [2002]. Although additional seismometer sites had been proposed, the final upgrade in 2004 maintained the existing geometry of the array, 
but with the deployment of three component seismometers at six of the nine sites and an increase of the sampling frequency from 40 to $80 \mathrm{~Hz}$. The increase in sampling rate was deemed necessary given the observation of high frequency signals (significant energy exceeding $14 \mathrm{~Hz}$ ) from events across the Barents Sea [Bowers et al., 2001]. The upgrade also involved the replacement of the short period sensors with broadband instruments. While there would be little array processing gain over the small aperture of SPITS for the lowest frequencies, this solution provides a redundancy such that the full spectrum for a given event can be recorded as long as at least one instrument is in operation.

The first data from the upgraded array is from August 11, 2004. Details of the instrumentation and the refurbishment are provided by Fyen [2004, 2005]. After several years of observation, including several low magnitude events providing an almost optimal coverage of the Novaya Zemlya region, we are able to evaluate the extent to which the refurbishment has improved the detection and classification of events from the eastern Barents Sea. In Section 2 we review some properties of the SPITS array that are central to routine processing and the problems that these can present for phase identification and association. The specific improvement to SNR for the Sn phases from Novaya Zemlya events using beamforming on the rotated horizontal component traces is addressed in Section 3. Section 4 examines how performing array analysis separately on the different component traces can identify detected phases much more reliably than is possible from parameter estimates using only the vertical component traces.

\section{Considerations in Operational Processing of the SPITS array}


The uppermost panels of Fig. 4 display the geometries of both ARCES and SPITS arrays. ARCES was built to the same design as the NORES regional array in southern Norway with instruments deployed in four concentric rings at increasing distances from a central site. This configuration provides a wide range of inter-site spacings with the intention that different subsets of sensors would provide optimal noise cancellation and optimal resolution in parameter estimates for different types of arrival. Detection of teleseismic phases, dominated by lower frequencies, could actually improve by omitting the instruments with the smallest inter-site spacings [c.f. Kvcrna, 1989] given the correlation properties of signal and noise. Similarly, the detection and estimation of higher frequency regional phases could be improved by omitting the outermost sites in order to mitigate the effects of signal incoherence. Economical and logistical constraints have meant that subsequent array deployments have had fewer instruments, despite the same design concept being maintained. Many of the arrays that have been deployed as IMS stations in recent years have consisted of nine sites arranged in two concentric rings around the central site. With the reduced number of sensors, a choice needs to be made as to whether the priority is detection and estimation of lower frequency teleseismic signals (for which a larger aperture is appropriate) or the detection and estimation of higher frequency regional phases (for which a smaller aperture is more appropriate). Increasing the array aperture lowers the maximum frequency at which coherent array processing can be performed and decreasing the array aperture reduces the slowness resolution for any coherent signal. Given the regional monitoring requirements for SPITS, it was clear that coherent processing for high frequency regional phases took precedence over slowness resolution for 
teleseismic signals (from events which are likely to be covered sufficiently by stations at smaller distances and by lower noise continental seismic arrays). The resulting array has an aperture slightly over $1 \mathrm{~km}$, among the smallest seismic arrays in the IMS.

The most important parameters for phase association and event location are the apparent velocity, $v_{\text {app }}$, and the backazimuth, $\Theta$, which are made more manageable in array processing using the horizontal slownesses $s_{x}$ and $s_{y}$ with

$$
s_{x}=s_{\mathrm{h}} \sin (\Theta) \quad s_{y}=s_{\mathrm{h}} \cos (\Theta)
$$

where the horizontal slowness scalar, $s_{\mathrm{h}}=1 / v_{\mathrm{app}}$, is the amplitude of the slowness vector

$$
\boldsymbol{s}_{\mathrm{h}}=\left(s_{x}, s_{y}\right)
$$

Under the plane wavefront assumption, a wavefront that arrives at the array reference site (with coordinate vector $\boldsymbol{r}_{0}$ ) at a time $t_{0}$ will arrive at site $i$ (with coordinate vector $\left.\boldsymbol{r}_{i}\right)$ at time

$$
t_{i}=t_{0}-\boldsymbol{s}_{\mathrm{h} \cdot\left(\boldsymbol{r}_{i}-\boldsymbol{r}_{0}\right)}
$$

For regional phases, $v_{\text {app }}$ is used primarily for phase identification. The accuracy with which $\Theta$ can be estimated determines suitable parameter ranges for phase association, and can also affect event location estimates significantly for sparse networks of arrays. The lowermost panels in Fig. 4 indicate the slowness resolution anticipated for each array for a seismic phase with a dominant frequency of $4 \mathrm{~Hz}$. It is assumed that the time-delays between sensors satisfy a plane-wave assumption perfectly and that wavelets incident over the array are identical (i.e. that the wavefront is perfectly coherent). The theoretical resolution in slowness for the ARCES array is clearly higher than that for the 
SPITS array, due to the larger array aperture, although the picture can be complicated significantly due to diminishing waveform coherence. In addition, the variability and bias of slowness estimates from f-k analysis can vary greatly from frequency band to frequency band [e.g. Kvarna and Doornbos, 1991] and calibrations for azimuth estimates ought to take into account the frequency band used [see Gibbons et al., 2010, and references therein]. Schweitzer and Kvcrna [2002] discuss alternatives that were considered for an upgrade of the SPITS array. While one of the recommendations was the deployment of additional 3-component seismometers at existing sites within the array, other suggestions (which were never carried out) included the deployment of additional sites. An additional ring of sensors at a greater aperture than the existing array was proposed to improve the slowness resolution, and additional sensors within the innermost ring were proposed to resolve high frequency local phases. Screening these local events, with a high level of confidence, would lead to a great improvement in the automatic processing at SPITS given the enormous number of these events. If not correctly identified, there is a risk that these local phases are interpreted as regional phases which can reduce the reliability of the phase association algorithms and automatic bulletins.

Seismometers in an ideal array will all be at the same elevation, although this is rarely achievable due to topography. The small changes in the theoretical travel-times resulting from the elevation differences can often be, and frequently are, ignored since the differences in elevation are usually small compared with the lateral inter-site distances. This is not the case for SPITS and slowness estimates may suffer significant bias if the additional traveltimes incurred are not properly accounted for. A detailed description of correcting 
for elevation differences is provided by Schweitzer et al. [2002]. The residuals between measured time-delays and those predicted without considering elevation differences are likely to be small but may be significant [e.g. Bear and Pavlis, 1999].

The time-delays predicted without correcting for elevation differences (Equation 3) are only a function of the apparent horizontal slowness vector $\boldsymbol{s}_{\mathrm{h}}$. The array may not, for example, be able to differentiate between a $\mathrm{P}$-wave from a local event, approaching at a shallow angle of incidence, from an S-wave from a deeper or more distant event, approaching at a steeper angle of incidence. When topography needs to be accounted for, we also need to consider the local wave speed, $v_{\text {loc }}$. Under the hypothesis that the arriving wavefront travels with a slowness $s=1 / v_{\text {loc }}$, there is a vertical component of the motion specified by

$$
s_{z}=\sqrt{\left(s^{2}-s_{x}^{2}-s_{y}^{2}\right)}
$$

where the angle of incidence, $\Theta_{i}$, is given by

$$
\Theta_{\mathrm{i}}=\tan ^{-1}\left(\frac{s_{\mathrm{h}}}{s_{z}}\right)
$$

The time-delay at sensor $i$ for any given $s_{x}, s_{y}$, and $v_{\text {loc }}$ which accounts for the elevation $\left(h_{i}\right)$ is given by

$$
t_{i}=t_{0}-\boldsymbol{s}_{\mathrm{h}} \cdot\left(\boldsymbol{r}_{i}-\boldsymbol{r}_{0}\right)+\left(\frac{1}{v_{\mathrm{loc}}^{2}}-s_{x}^{2}-s_{y}^{2}\right)^{\frac{1}{2}}\left(h_{i}-h_{0}\right)
$$

where $h_{0}$ is the elevation of the reference site of the array. $s_{z}$ is only defined for the parts of $\left(s_{x}, s_{y}\right)$-space for which $s_{x}^{2}+s_{y}^{2} \leq 1 / v_{\text {loc }}^{2}$ such that the slowness grid which needs to be searched for the presence of either P- or S-waves is smaller than the grid searched for 
general plane wavefronts. However, we need to calculate a separate measure of semblance or beam-gain over two grids: one for local P-wave speed and one for local S-wave speed.

Fig. 5 shows the effects of accounting for elevation corrections for both the Pn and Sn phase arrivals (in the left and right hand panels respectively) from one of the Novaya Zemlya events in Table 1. All waveforms from the short period vertical sensors were bandpass filtered between 3.0 and $8.0 \mathrm{~Hz}$ and then resampled to a rate of $200 \mathrm{~Hz}$. A three second long waveform segment was selected for each channel at both of the times specified, and a fully normalized cross-correlation coefficient trace was evaluated for each pair of channels. For each slowness vector $\left(s_{x}, s_{y}\right)$ time-delays were calculated using Eq. 3 for the top row of panels (with no local wave speed specified) and using Eq. 6 for the remaining panels (with assumed local wave speed as indicated). Note the limited loci of slowness vector space over which the fixed wave speed estimates are valid. The color at each point in the slowness vector grid indicates the mean value of the cross-correlation traces evaluated according to the appropriate time-delays [denoted XCORR by Frankel et al., 1991]. The arrow in each of the panels points to the slowness vector for which the value of XCORR is a maximum. Considering firstly the panels in the left hand column, the backazimuth varies from 99.5 degrees (for the calculation ignoring elevation differences) to 86.2 degrees (for the calculation assuming a wavefront propagating with a local S-wave speed). The highest value of XCORR is achieved for the central panel where a P-wave speed is assumed. The right hand panels of Fig. 5 show the equivalent slowness grids for the estimated arrival time of the Sn phase. The maximum XCORR values are significantly less for the S-phase than the P-phase [as is frequently observed, 
see e.g. Ringdal and Husebye, 1982]. Some variability in the backazimuth and apparent velocity is also seen for the Sn phase, if somewhat less than for Pn. The greatest value of XCORR is observed for the calculation with assumed S-wave velocity.

It should be noted that the mean cross-correlation coefficient denoted XCORR by Frankel et al. [1991] is just one of many possible measures of waveform alignment [see for example Rost and Thomas, 2002, 2009, for a discussion of different techniques]. Numerous methods, both in the time and frequency domains, have been applied to SPITS data and we have yet to identify one technique which provides consistently better slowness estimates than any other method. The method of Frankel et al. [1991] considers fully normalized cross-correlation coefficient traces and may be less susceptible to anomalously large amplitudes on any one sensor than alternative measures of waveform similarity which are more sensitive to the amplitudes on individual channels. In routine processing at NORSAR, slowness vectors on small aperture arrays are usually estimated using broadband f-k analysis [e.g. Kvarna and Ringdal, 1986; Kennett, 2002], computed in the frequency domain, where the returned parameter is a "relative beam power" giving the maximum ratio of the energy in the beam steared with the optimal time-delays to the mean energy of the individual traces.

It must be stressed that the backazimuth inferred from the slowness grid with the most appropriate local wavespeed assumption is not necessarily the estimate that is closest to the great-circle backazimuth. A deviation of the approaching wavefront from the geographical backazimuth is likely to result from geological features along the propagation path. The greatest contribution is likely to arise from structure directly below the ar- 
ray [see, for example, Niazi, 1966; Kvarna and Doornbos, 1991]. However, it is always beneficial to calculate the time-delays which optimize the alignment of the waveforms since these are more likely to give an accurate description of the direction with which the wavefront approaches the array. The left hand panels of Fig. 5 indicate that imposing no local wave speed, or an inappropriate local wave speed, leads not only to a decrease in the maximum value of XCORR (i.e. a misalignment of waveforms) but a change of up to several degrees for the backazimuth estimate. It must also be noted that despite improving the waveform alignment, the heuristic correction terms specified in Eq. 6 are themselves an oversimplified parameterization and that a fully-empirical mapping of time-delays [see, e.g. VanDecar and Crosson, 1990] is likely to provide a better waveform alignment for regions of slowness space for which many observations are available. Bear and Pavlis [1999] propose a dual time- and frequency-domain procedure for waveform realignment, although the simple fixed local wave speed elevation corrections presented here are likely to provide a good initial estimate.

An ideal seismic array would provide an accurate backazimuth measurement together with an estimate for $v_{\text {app }}$ which identifies the phase unambiguously. Significant bias in both slowness and azimuth was observed almost from the start of processing data from the large aperture arrays [see Berteussen, 1976, and references therein] and the problems persist to smaller aperture arrays [Schweitzer, 2001]. Figure 6 illustrates how apparent velocity estimates of the four major regional phases (Pn, Pg, Sn, Lg) vary as a function of backazimuth for the ARCES and SPITS arrays for events in the NORSAR reviewed regional event bulletin. The backazimuth used is the great-circle backazimuth 
inferred from the analyst locations in the bulletin and the phase onset times and labels are those provided by the analyst. However, the slowness estimates themselves have been recalculated in order to mitigate a number of sources of variability. Firstly, fixed frequency bands have been used for each of the phases. The bands chosen will not be optimal for every source region, but should result in a far greater consistency for multiple signals from a single source region [Gibbons et al., 2010]. Secondly, the fixed local wavespeed parametrization described above has been applied to try to reduce the consequences of elevation differences between the different sites. Note that Figure 6 displays the fixed frequency band estimates for all phases in the reviewed bulletin between 2006 and 2008 .

In addition to issues of event location, phase identification, and other considerations in parameter estimation, there is another significant proviso to the interpretation of Figure 6 . No account is taken of the epicentral distance; no distinction is made between a Pn phase from an event at $300 \mathrm{~km}$ and an event at $1500 \mathrm{~km}$. For example, the apparent velocities for Pn phases at ARCES between 100 and 150 degrees backazimuth are somewhat lower than those between 310 and 360 degrees backazimuth. However, given the disparity of distances to the different source regions in these two directions (Figure 1), it is dangerous to attribute the near-sinusoidal variation in slowness exclusively to possible dipping structures [c.f. Niazi, 1966; Zengeni, 1970]. Most significantly for ARCES, there is a clear separation for all backazimuths for both P- and S- phases allowing a comfortable identification of primary and secondary phases based on the apparent velocity alone.

The close sinusoidal variation in velocity estimates for SPITS is far greater than for ARCES and, given the smaller disparity of epicentral distances in the dataset, it is also 
more easily attributable to structures below the array. Both $\mathrm{P}$ and $\mathrm{S}$ velocities vary similarly with azimuth [Figure 9 of Schweitzer, 2001, demonstrates the variation for P-phases] although it is clear that no single apparent velocity can be specified as a boundary between $\mathrm{P}$ and $\mathrm{S}$ phases. For some ranges of backazimuth, there is significantly overlap between estimates for $\mathrm{P}$ and $\mathrm{S}$ estimates from the same direction. By far the most anomalous estimates are for the North West direction (290-360 degrees) for which both regional Pn and Sn phases result in velocity estimates normally associated with teleseismic P phases. This is likely to have led to a more incomplete automatic event bulletin for this region since the phase identifications are frequently qualitatively misleading.

\section{Improved Detection of S-phases using Beams of Rotated Traces}

Figure 7 displays beams at SPITS for the six significant events at or near Novaya Zemlya since the upgrade of the array (Table 2). Unlike for Figure 2, three beams are provided for each event. Two different beams are provided for each secondary phase: one using the vertical sites only, and one using the horizontal components rotated perpendicular to the great-circle path to the event location. The SNR measurements quoted for the different phases are local maxima of the STA to LTA ratio. In the optimized online detection processes, the SNR measurements obtained are frequently greater than those displayed here since a larger delay between the STA and LTA is often introduced to prevent an increase in the LTA due to the onset of an emergent signal [see Schweitzer et al., 2002]. However, the contrast between the SNR values displayed for the different traces in Figure 7 is quite informative since higher values for the short-delay SNR measurements 
are indicative of more impulsive arrivals which are more useful in accurate arrival time estimation.

For each of the events in Figure 7, a higher value for the Sn-phase SNR is obtained on the transverse horizontal beam than on the vertical beam. Not only is the amplitude of Sn greater on the transverse rotation, the amplitude of the P-coda is significantly lower resulting in a far clearer distinction between signal and noise at the time of the Sn arrival. Only the Sn phase for Event 1 provides an SNR significantly higher than a typical detection threshold of 3.0 on the beam of vertical traces. In contrast, all of the events except Event 2 result in a clear secondary phase detection on the transverse beam. The secondary phase for Event 2 is marginal on both the vertical and transverse beams, although identification on the transverse beam is helped by the absence of the P-phase and coda.

Figure 8 displays spectrograms for the vertical and horizontal traces from the SPB1 site for Event 1. We note firstly the significant energy of both Pn and Sn arrivals above $20 \mathrm{~Hz}$ (the Nyquist frequency of the old instrumentation). The high frequency signal is only visible because of the upgrade and may provide important information regarding source identification as and when signals from subsequent events are observed. The presence of high frequency energy may be important in assessing the source type. Since it is demonstrated here that these high frequencies can travel these distances in this region, the absence of the high frequency data for previous events is unfortunate. For all frequencies, there is more $\mathrm{P}$ than $\mathrm{S}$ energy on the vertical trace and more $\mathrm{S}$ than $\mathrm{P}$ energy on the transverse trace. However, the contrast in energy between the P-coda and Sn 
arrival is far greater at the lower frequencies on the transverse trace than on the vertical trace. On the vertical trace, the significant energy for the Sn arrival is at and above 10 Hz. This high-frequency energy is scattered and often incoherent, even over this small aperture array, making beamforming ineffective and direction estimation difficult. On the horizontal trace, the greatest SNR for the Sn phase is found for the 2-5 Hz band. This has implications for detection and direction estimation since the waveforms are far more coherent in this frequency band, making beamforming far more effective.

\section{Resolving Ambiguity in Phase Identification}

We have demonstrated that secondary phases at SPITS for events in the eastern Barents Sea are far more easily discerned with the help of the horizontal traces. However, there are other source regions from which the S-phases are barely visible at all on the vertical components. Figure 9 displays SPITS waveforms and corresponding slowness grids for an event on Mohns Ridge at a distance of approximately $800 \mathrm{~km}$ from the array (location labelled MR in Figure 1). The predicted Sn-arrival is barely registered above the background noise level on either of the vertical trace beams and performing $\mathrm{f}-\mathrm{k}$ analysis on the vertical component channels does not result in a slowness estimate that is qualitatively indicative of a secondary phase from the anticipated direction. If the horizontal channels are rotated in the appropriate direction, a pulse of energy significantly above the level of the P-coda is observed at the predicted arrival time for Sn. Although still weak compared with the Pn-arrival and coda, it is strong enough to be detected and to provide a slowness estimate indicative of a secondary phase arriving from almost the same direction as the P-phase. The slowness estimate on the horizontal traces in Figure 9 at the time of the 
Sn-arrival could be deemed to be of higher quality than the corresponding estimate on the vertical traces based upon the value of the relative beam power.

In Figure 5, we select the slowness vector providing the greatest value of a waveform similarity measure from multiple $\left(s_{x}, s_{y}\right)$ grids, in each of which the time-delays are calculated assuming a different value of the local wave speed. Similarly, in Figure 9, it is reasonable to assume that the slowness grid providing the highest coherence measure (be it relative beam power, mean correlation coefficient, or F-statistic) is likely to provide the most reliable indication of the nature of the arriving wavefront. The vertical component $\mathrm{f}-\mathrm{k}$ analysis indicates the apparent velocity of a regional $\mathrm{P}$-wave whereas the horizontal component estimate indicates a regional S-wave, with the S-wave being deemed more likely on the basis of the chosen coherence measurement. For a comprehenive examination of an unknown phase, many different slowness grids should be considered. If an initial estimate of the backazimuth is not available, alternative grids should be calculated based upon rotations in numerous different directions. It may be sufficient to consider only the N-S and E-W components, although it is likely that even greater coherence between horizontal seismograms can be obtained for rotations closer to the true backazimuth. (Only backazimuths between zero and 90 degrees need be considered since symmetry considerations cover all other directions given both the transverse and radial components.)

The lower panel of Figure 6 indicates directions from which $\mathrm{P}$ and $\mathrm{S}$ phases propagate over the SPITS array which can not easily be differentiated based upon apparent velocity alone. The most problematic directions are to the north west, between 280 and 360 degrees backazimuth, from which both regional $\mathrm{P}$ and $\mathrm{S}$ phases cross the array with 
apparent velocities usually attributed to teleseismic P-phases. A geological feature which causes regional phases to approach the array at a steep angle of incidence clearly provides resolution difficulties considering the small aperture of SPITS (c.f. Figure 4). An example of such an event (with a backazimuth of around 330 degrees) is displayed in Figure 10. Unlike the case for the Mohns Ridge event (Figure 9), the problem is not primarily the signal-to-noise ratio for the secondary phases. While the horizontal S beams improve the SNR dramatically, the Sn onset is clearly visible on the vertical beam. The problem is that $\mathrm{f}-\mathrm{k}$ analysis on the vertical seismometers at the time of the $\mathrm{Sn}$ arrival is not qualitatively indicative of any coherent phase, whereas the transverse $\mathrm{f}-\mathrm{k}$ analysis (with otherwise identical processing parameters) does indicate a coherent phase approaching the array from the same direction as the earlier Pn arrival, with a lower apparent velocity.

The upper panel of Figure 11 is a zoom-in of a portion of the lower panel of Figure 6 considering only Pn and Sn phases. Here it is clear that no line can be drawn which separates the white and the black symbols, and hence that Pn and Sn phases from this range of directions are indistinguishable on the grounds of apparent velocity alone. If, instead of using the vertical component only, we measure the apparent velocity using slowness grids for both horizontal and vertical components and taking the value corresponding to the greatest measure of coherence (middle panel) then the black and white symbols do separate somewhat. However, the extent of the parameter space corresponding to either Pn or Sn phases appears to vary significantly with backazimuth such that any rules of phase selection based upon apparent velocity would need to be calibrated carefully. The lower panel indicates that the most effective selection criterion is simply a ratio between 
the coherence of the vertical components and the coherence of the horizontal components. With only a few exceptions, all Pn phases appear to have more coherent vertical components and all Sn phases appear to have more coherent horizontal components. For each detection, if the multiple f-k grids are computed and the phase name attributed according to the rotation of waveforms providing the greatest measure of coherence, it would appear that almost all phases are classified correctly even when the apparent velocity measured directly is not consistent with the anticipated slowness vector.

Applying this procedure to the online processing of SPITS data should reduce significantly the number of phases which are classified incorrectly and therefore improve the completeness of seismic bulletins for the European Arctic.

\section{Conclusions}

The SPITS array is of fundamental importance in maintaining a low seismic detection threshold for the European Arctic region. This is likely to remain the case for the foreseeable future. The few available land sites within regional distances of the eastern Barents Sea and Novaya Zemlya are accessed with great difficulty and are almost always characterized by high noise levels due to the proximity of the sea. The safe detection of events below magnitude 3 in the region requires both the ARCES and SPITS arrays to be in operation, although events can be detected using a single array if both Pn and Sn phases are detected and attributed estimates of backazimuth and apparent velocity that are of sufficiently high quality to facilitate phase association with a low false alarm rate. The need to detect and correctly identify Sn phases is made more acute by the Lg-blockage of the Barents Sea. 
We have reviewed some of the most important considerations in optimal processing of data from the SPITS array, including the necessity of taking account of elevation differences when performing beamforming and f-k analysis. An upgrade of SPITS in 2004 resulted in the deployment of 3-component seismometers at 6 out of the 9 sites, facilitating array processing on rotated horizontal components in addition to the vertical sensors. With reference to six events in or close to Novaya Zemlya since 2006, we demonstrate the improvement in the detectability of the secondary phases using beams of the horizontal traces. Increasing the number of 3-component sensors at other IMS seismic arrays would be likely to show a similar improvement of performance in terms of the detection and estimation of S-phases. The multiple horizontal sensors have also resulted in a partial redundancy which reduces the severity of failure at one or more sites.

One unfortunate property of SPITS array for the purpose of automatic phase detection and identification is the significant azimuthal variation of the apparent velocity of regional phases. This is quite characteristic of many arrays but rarely presents a problem since apparent velocities of the regional $\mathrm{P}$ and $\mathrm{S}$ phases generally occupy different regions of the slowness vector space. This is not the case for SPITS and, for many source regions, $\mathrm{P}$ and S phases are not distinguishable based upon the apparent velocity alone. The problem is most acute for the region to the north west of SPITS for which both regional $\mathrm{P}$ and S phases cross the array with apparent velocities characteristic of teleseismic P-phases. For such events, the comparison of the coherence between vertical components and the coherence between horizontal components appears to provide a better separation between Pn and Sn phases than the actual values of the apparent velocity obtained. For this and 
other source regions, $\mathrm{f}-\mathrm{k}$ analysis of S-phases on the vertical components frequently fails with P-type apparent velocities resulting for time-intervals where horizontal component $\mathrm{f}-\mathrm{k}$ analysis results in S-type apparent velocities.

It should be noted that all of the results in this paper have been achieved using only analysis on a single rotation at any given time. This is to say that no exploitation has yet been made of polarization information [e.g. Jurkevics, 1988]. The difficulty in differentiating between, for example, Pn and Sn phases within the same wavetrain can be viewed mathematically as being caused by an insufficient distance between the principal eigenvectors of the spectral covariance matrices evaluated over the two time-windows. The elements of the covariance matrices describing the phase differences between like components at different sites are modelled by the plane-wavefront assumption, together with heuristic modifications to accomodate corrections for elevation. There is no straightforward way to model the cross-elements of the spectral covariance matrices, describing the phase and/or amplitude differences between different components of ground motion at the different sites. However, Harris and Kvarna [2010] provide compelling evidence for the ability to classify phases based upon an empirical matching between an unknown phase and a database of covariance matrices evaluated for previously observed and identified phases. The 3-component array covariance matrices for the Pn and Sn phases are likely to differ far more than the corresponding single component covariance matrices since they include implicitly the differences in polarization between sensors, even if this level of detail is beyond what a model can realistically describe. A 3-component array is likely to be 
able to differentiate between phases using an empirical matched field processing approach far better than a single-component array could.

Substantially more work will be required to determine optimal parameters for detection and estimation using the 3-components of the array. For a vertical-only array, the timedelays applied are the only parameters which control the improvement of the SNR on the array beams. The density of beam deployments necessary can be estimated from a consideration of the array response function (see Figure 4). With a three-component array, there are numerous transformations that can be performed at each site prior to beamforming [see Kim et al., 1997] which may optimize the SNR for a given type of phase. The SNR for the secondary phases has been demonstrated to be significantly better on the horizontal components than on the vertical components, although only an optimal transverse rotation has been used in the cases displayed. The SNR will depend both on the time-delays applied and on the rotation of the horizontal components. It is usually assumed that the SNR on the transverse component will be superior to that on the radial component as it is likely to be less susceptible to converted phases and noise from the P-coda. However, this will need to be investigated systematically for many different signals; it is likely that the SNR ratio between transverse and radial components will vary from signal to signal. In the current pipeline detection process, f-k calculations on the horizontal components are performed with the rotation angle determined by the detecting beam. It may be that separate $\mathrm{f}-\mathrm{k}$ calculations on numerous different rotations may be advisable. 
In this paper, we have considered only the capability to detect and locate seismic events and have not speculated on the nature of any of the events listed in tables 1 and 2 . Event D in Table 1, the Kara Sea event of 16 August 1997, has received the greatest amount of attention and it is widely believed that the event was an earthquake, both due to the nature of the signals generated [Bowers, 2002], the occurrence of a small aftershock some four hours later [Richards and Kim, 1997], and a probable depth between $10 \mathrm{~km}$ and $30 \mathrm{~km}$ in the crust [Schweitzer and Kennett, 2007]. Ringdal et al. [2002] note that observations from events in the region demand that caution is necessary when attempting to apply classical discriminants, particularly at lower magnitudes. However, the seismic data recorded by the upgraded SPITS array, both in terms of representation of higher frequencies and the new three-component sensors, presents a far richer source of information from which future discriminants may be developed. Kim et al. [1997] demonstrate the improvement to discriminants possible when the different rotations of three-component seismograms can be exploited. However, such information only becomes useful for the purpose of comparison as and when new observations are made. 


\section{Footnote for table 1}

Detected seismic events located on or close to Novaya Zemlya following the installation of the SPITS array, but prior to the upgrade in 2004. The ID letter identifies the location

estimate provided in Fig. 1. Event estimates provided by NORSAR [see, in addition, Ringdal, 1997; Schweitzer and Kennett, 2007].

\section{Footnote for table 2}

Detected seismic events located on or close to Novaya Zemlya since the upgrade of the SPITS array in 2004. The ID number identifies the location estimate provided in Fig. 1. [see Gibbons, 2006, for a discussion of event number 1]. 


\section{Data and Resources}

All maps in this paper are created using GMT software [Wessel and Smith, 1995].

The event locations is displayed are taken from the NORSAR Reviewed Regional Event Bulletin available at

http://www.norsardata.no/NDC/bulletins/regional/ (last referenced July 2011).

Waveform data from the SPITS array is openly available from http://www.norsardata.no/NDC/data/autodrm.html (last referenced July 2011).

Acknowledgments. We thank Neil Selby and an anonymous reviewer for constructive comments which we believe have improved the paper considerably. 


\section{References}

Baumgardt, D. R., Sedimentary basins and the blockage of Lg wave propagation in the continents, Pure appl. geophys., 158, 1207-1250, doi:10.1007/PL00001221, 2001.

Bear, L. K., and G. L. Pavlis, Multi-channel estimation of time residuals from broadband seismic data using multi-wavelets, Bull. Seism. Soc. Am., 89, 681-692, 1999.

Berteussen, K. A., The origin of slowness and azimuth anomalies at large arrays, Bull. Seism. Soc. Am., 66, 719-741, 1976.

Bowers, D., Was the 16 August 1997 Seismic Disturbance near Novaya Zemlya an Earthquake?, Bull. Seism. Soc. Am., 92(6), 2400-2409, doi:10.1785/0120020012, 2002.

Bowers, D., P. D. Marshall, and A. Douglas, The level of deterrence provided by data from the SPITS seismometer array to possible violations of the Comprehensive Test Ban in the Novaya Zemlya region, Geophys. J. Int., 146, 425-438, doi:10.1046/j.1365246x.2001.01462.x, 2001.

Engen, Ø., O. Eldholm, and H. Bungum, The Arctic plate boundary, J. Geophys. Res., 108(B2), 2075, doi:10.1029/2002JB001809, 2003.

Frankel, A., S. Hough, P. Friberg, and R. Busby, Observations of Loma Prieta Aftershocks from a Dense Array in Sunnyvale, California, Bull Seism Soc Am, 81(5), 1900-1922, 1991.

Fyen, J., Selection of seismometers for Spitsbergen array refurbishment, NORSAR Scientific Report: Semiannual Technical Summary, 1 July - 31 December 2003 No. 1 - 2004, NORSAR, Kjeller, Norway, pp. 26-31, 2004. 
Fyen, J., Spitsbergen array refurbishment, NORSAR Scientific Report: Semiannual Technical Summary, 1 July - 31 December 2004 No. 1 - 2005, NORSAR, Kjeller, Norway, pp. 24-33, 2005.

Gibbons, S. J., On the Identification and Documentation of Timing Errors: An Example at the KBS Station, Spitsbergen, Seism. Res. Lett., 77, 559-571, doi:10.1785/gssrl.77.5.559, 2006.

Gibbons, S. J., T. Kværna, and F. Ringdal, Considerations in Phase Estimation and Event Location Using Small-Aperture Regional Seismic Arrays, Pure appl. geophys., 167, 381-399, doi:10.1007/s00024-009-0024-1, 2010.

Harris, D. B., and T. Kværna, Superresolution with Seismic Arrays using Empirical Matched Field Processing, Geophys. J. Int., 182, 1455-1477, doi:10.1111/j.1365246X.2010.04684.x, 2010.

Jurkevics, A., Polarization analysis of three-component array data, Bull. Seism. Soc. Am., 78, 1725-1743, 1988.

Kennett, B. L. N., The Seismic Wavefield. Volume II: Interpretation of Seismograms on Regional and Global Scales, Cambridge University Press, 2002.

Khalturin, V. I., T. G. Rautian, P. G. Richards, and W. S. Leith, A Review of Nuclear Testing by the Soviet Union at Novaya Zemlya, 1955-1990, Science and Global Security, 13, 1-42, doi:10.1080/08929880590961862, 2005.

Kim, W.-Y., V. Aharonian, A. L. Lerner-Lam, and P. G. Richards, Discrimination of Earthquakes and Explosions in Southern Russia Using Regional High-Frequency ThreeComponent Data from the IRIS/JSP Caucasus Network, Bull. Seism. Soc. Am., 87, 
569-588, 1997.

Kværna, T., On exploitation of small-aperture NORESS type arrays for enhanced P-wave detectability, Bull. Seism. Soc. Am., 79, 888-900, 1989.

Kværna, T., and D. J. Doornbos, Scattering of Regional Pn by Moho Topography, Geophys. Res. Lett., 18, 1273-1276, doi:10.1029/91GL01292, 1991.

Kværna, T., and F. Ringdal, Stability of various f-k estimation techniques, NORSAR Scientific Report: Semiannual Technical Summary No. 1 - 1986/1987, NORSAR, Kjeller, Norway, pp. 29-40, 1986.

Kværna, T., J. Schweitzer, L. Taylor, and F. Ringdal, Monitoring of the European Arctic Using Regional Generalized Beamforming, NORSAR Scientific Report: Semiannual Technical Summary, 1 October - 31 March 1999 No. 2 - 1998/1999, NORSAR, Kjeller, Norway, pp. 78-94, 1999.

Kværna, T., F. Ringdal, J. Schweitzer, and L. Taylor, Optimized Seismic Threshold Monitoring - Part 1: Regional Processing, Pure appl. geophys., 159, 969-987, doi:10.1007/s00024-002-8668-0, 2002.

Marshall, P. D., R. C. Stewart, and R. C. Lilwall, The seismic disturbance on 1986 August 1 near Novaya Zemlya: a source of concern?, Geophys. J., 98, 565-573, doi:10.1111/j.1365-246X.1989.tb02290.x, 1989.

Mykkeltveit, S., and H. Bungum, Processing of Regional Seismic Events Using Data from Small-Aperture Arrays, Bull. Seism. Soc. Am., 74(6), 2313-2333, 1984.

Mykkeltveit, S., F. Ringdal, T. Kværna, and R. W. Alewine, Application of regional arrays in seismic verification research, Bull Seism Soc Am, 80, 1777-1800, 1990. 
Niazi, M., Corrections to apparent azimuths and travel-time gradients for a dipping Mohorovicic discontinuity, Bull. seism. Soc. Am., 56, 491-509, 1966.

Richards, P. G., and W.-Y. Kim, Testing the nuclear test-ban treaty, Nature, 389, 781782, doi:10.1038/39720, 1997.

Ringdal, F., Study of low-magnitude seismic events near the Novaya Zemlya test site, Bull Seism Soc Am, 87, 1563-1575, 1997.

Ringdal, F., and E. S. Husebye, Application of Arrays in the Detection, Location, and Identification of Seismic Events, Bull. Seism. Soc. Am., 72, S201-S224, 1982.

Ringdal, F., and T. Kværna, A multi-channel processing approach to real time network detection, phase association, and threshold monitoring, Bull. Seism. Soc. Am., 79, 19271940, 1989.

Ringdal, F., E. Kremenetskaya, and V. Asming, Observed characteristics of regional seismic phases and implications for $\mathrm{p} / \mathrm{s}$ discrimination in the european arctic, Pure appl. geophys., 159, 701-719, doi:10.1007/s00024-002-8655-5, 2002.

Rost, S., and C. Thomas, Array Seismology: Methods and Applications, Rev. Geophys., 40(3), 1008, doi:10.1029/2000RG000100, 2002.

Rost, S., and C. Thomas, Improving Seismic Resolution Through Array Processing Techniques, Surv. Geophys., 30, 271-299, doi:10.1007/s10712-009-9070-6, 2009.

Schweitzer, J., Tuning the automatic data processing for the Spitsbergen array (SPITS), NORSAR Scientific Report: Semiannual Technical Summary, 1 April - 30 September 1998 No. 1 - 1998/1999, NORSAR, Kjeller, Norway, pp. 110-125, 1998. 
Schweitzer, J., Slowness Corrections - One Way to Improve IDC Products, Pure appl. geophys., 158, 375-396, doi:10.1007/PL00001165, 2001.

Schweitzer, J., and B. L. N. Kennett, Comparison of Location Procedures: The Kara Sea Event of 16 August 1997, Bull. seism. Soc. Am., 97, 389-400, doi:10.1785/0120040017, 2007.

Schweitzer, J., and T. Kværna, Design Study for the Refurbishment of the SPITS Array (AS 72), NORSAR Scientific Report: Semiannual Technical Summary, 1 January - 30 June 2002 No. 2 - 2002, NORSAR, Kjeller, Norway, pp. 65-77, 2002.

Schweitzer, J., J. Fyen, S. Mykkeltveit, and T. Kværna, Chapter 9: Seismic Arrays, in IASPEI New Manual of Seismological Observatory Practice, edited by P. Bormann, GeoForschungsZentrum, Potsdam, 52 pp., 2002.

Storchak, D. A., J. Schweitzer, and P. Bormann, The IASPEI Standard Seismic Phase List, Seismological Research Letters, 74, 761-772, 2003.

Thomson, D. J., Spectrum Estimation and Harmonic Analysis, Proc. IEEE, $70(9)$, 10551096, 1982.

VanDecar, J. C., and R. S. Crosson, Determination of Teleseismic Relative Phase Arrival Times Using Multi-Channel Cross-Correlation and Least Squares, Bull. seism. Soc. Am., 80, 150-169, 1990.

Wessel, P., and W. H. F. Smith, New version of the Generic Mapping Tools, EOS Trans. Am. Geophys. Union, 76, 329, 1995.

Zengeni, T. G., A note on an azimuthal correction for $\mathrm{dT} / \mathrm{dDelta}$ for a single dipping plane interface, Bull. seism. Soc. Am., 60, 299-306, 1970. 
Table 1. Events prior to SPITS upgrade.

ID Lat. Lon. Date/Origin time Mag.
A $\quad 73.614 \quad 55.179$ December 31 1992-366:09.29.24.00 2.7
B $\quad 71.856 \quad 55.685 \quad$ February 13 1995-054:21.50.00.00 2.7
C $\quad 75.170 \quad 56.740 \quad$ June 13 1995-164:19.22.37.90 3.5
D $\quad 75.240 \quad 56.660 \quad$ January 13 1996-013:17.17.23.00 2.4
E $72.510 \quad 57.550 \quad$ August 16 1997-228:02.11.00.00 3.5
F $\quad 72.510 \quad 57.550 \quad$ August 16 1997-228:06.19.10.00 2.6
G $\quad 74.301 \quad 55.215 \quad$ February 13 2002-054:01.21.18.75 3.0
H $\quad 73.720 \quad 56.870 \quad$ July 27 2002-208:18.20.45.00 2.0
J $\quad 70.880 \quad 47.410$ November 10 2002-314:11.04.47.00 2.0
K $\quad 75.645 \quad 63.345 \quad$ October 08 2003-281:23.07.10.00 2.5 
Table 2. Events post SPITS upgrade.

ID Lat. Lon. Date/Origin time Mag.

$1 \quad 76.799 \quad 64.297 \quad$ March 5 2006-064:23.17.35.73 2.6

$2 \quad 75.072 \quad 53.056 \quad$ March 14 2006-073:20.57.02.41 2.2

$3 \quad 70.793 \quad 51.500 \quad$ March 30 2006-089:10.46.02.82 2.3

$4 \quad 73.388 \quad 53.389 \quad$ June 26 2007-177:03.19.19.48 2.8

$5 \quad 71.521 \quad 46.467$ November 11 2009-315:04.18.21.03 3.1

$6 \quad 76.245 \quad 62.815 \quad$ October 11 2010-284:22.48.30.95 4.5 


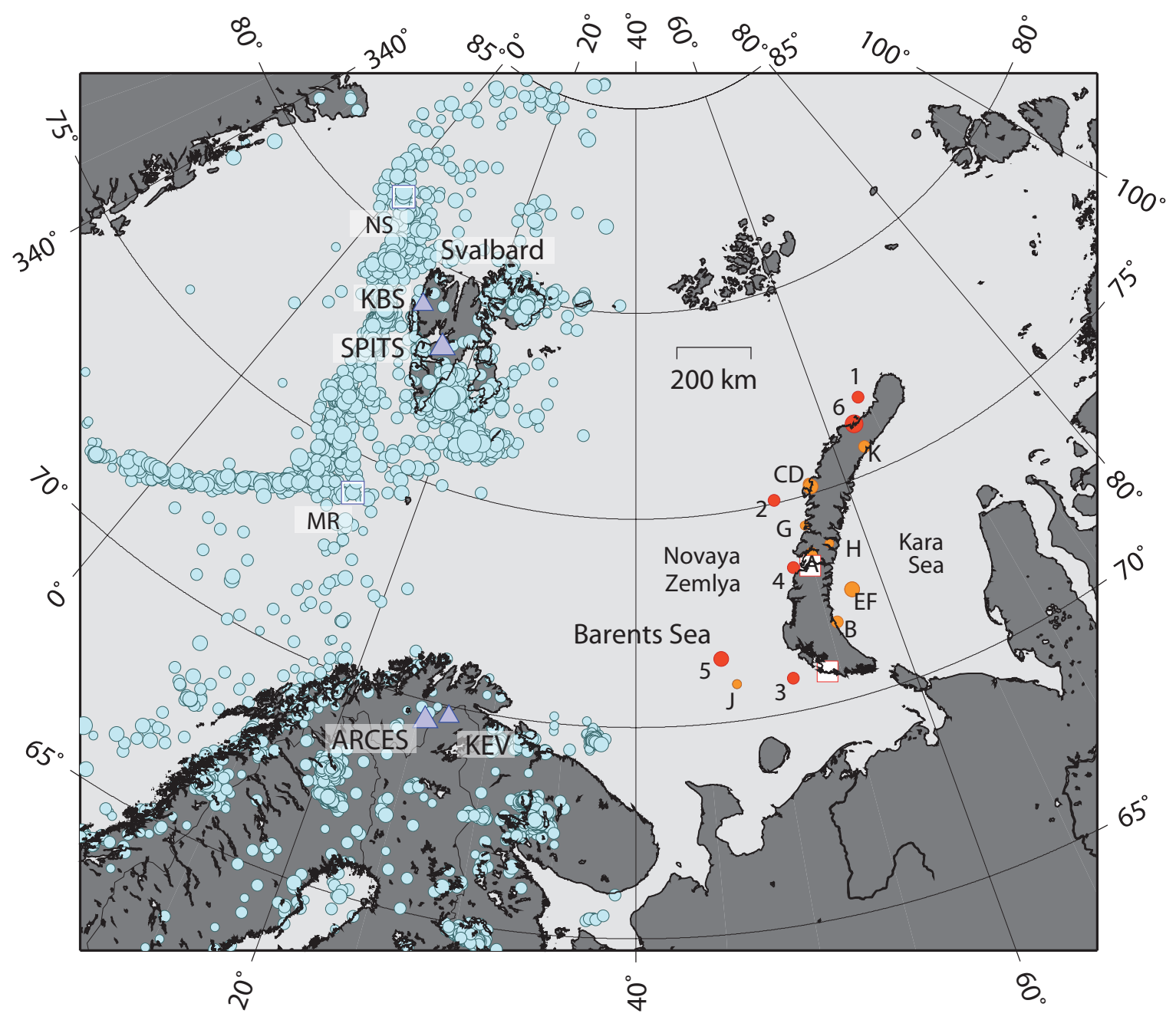

Figure 1. Location of the SPITS and ARCES arrays in relation to Novaya Zemlya, the former Soviet nuclear test sites, and seismicity in the European Arctic. The locations of the IRIS 3-C stations KEV (Kevo, Finland) and KBS (Kings Bay, Ny Ålesund, Svalbard) are also shown. The blue symbols indicate location estimates of seismic events from the NORSAR reviewed regional event bulletin between 1998 and 2008. The red/white squares indicate the approximate locations of North and South Soviet nuclear test sites on Novaya Zemlya. The letters A-K refer to the event IDs provided in Table 1 (events on or close to Novaya Zemlya prior to the SPITS upgrade) and the numbers 1-6 refer to the event IDs provided in Table 2 (events on or close to Novaya Zemlya following the SPITS upgrade). D R A F T November 9, 2017, 8:39pm The squares labelled MR and NS indicate the locations of two events (on Mohns Ridge and to the North of Svalbard) which are discussed later. Symbol size relates to event magnitude. 


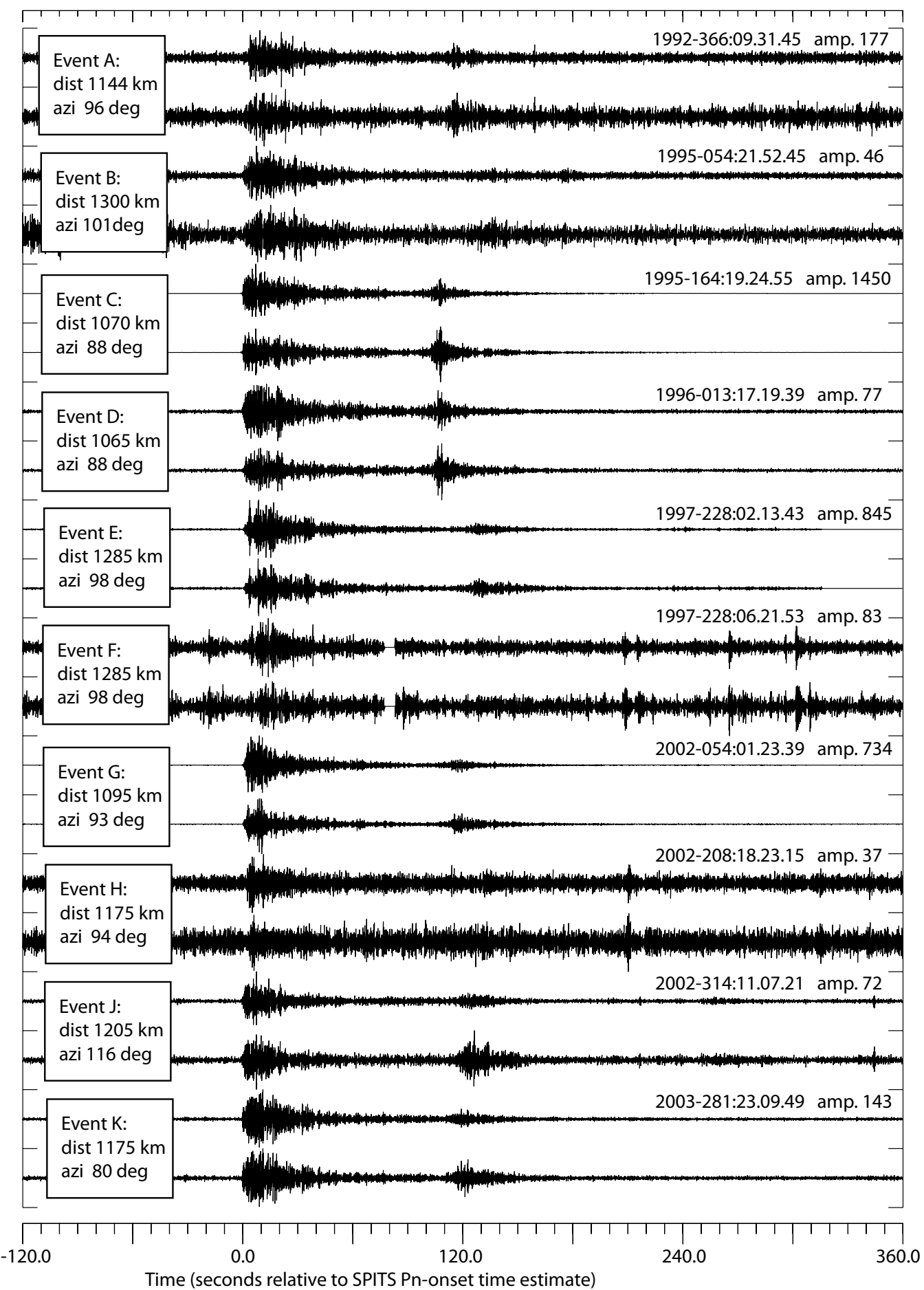

Figure 2. Beams on the short period vertical sensors of SPITS for the events listed in Table 1. For each event, the upper trace (labelled with the Pn arrival time estimate) is the beam steered to maximize the ampitude for the Pn arrival, bandpass filtered 4-8 Hz. The

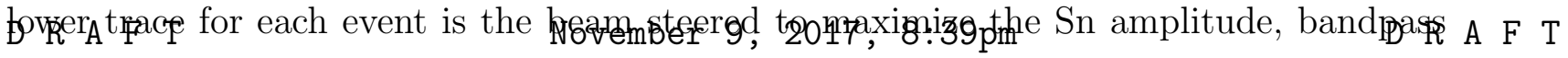
filtered 3-6 Hz. The only exception is Event H, for which both traces are bandpass filtered 5-10 Hz. The site SPB4 is subject to substantially higher environmental noise than the other sites in these frequency bands and this trace was removed prior to forming beams 


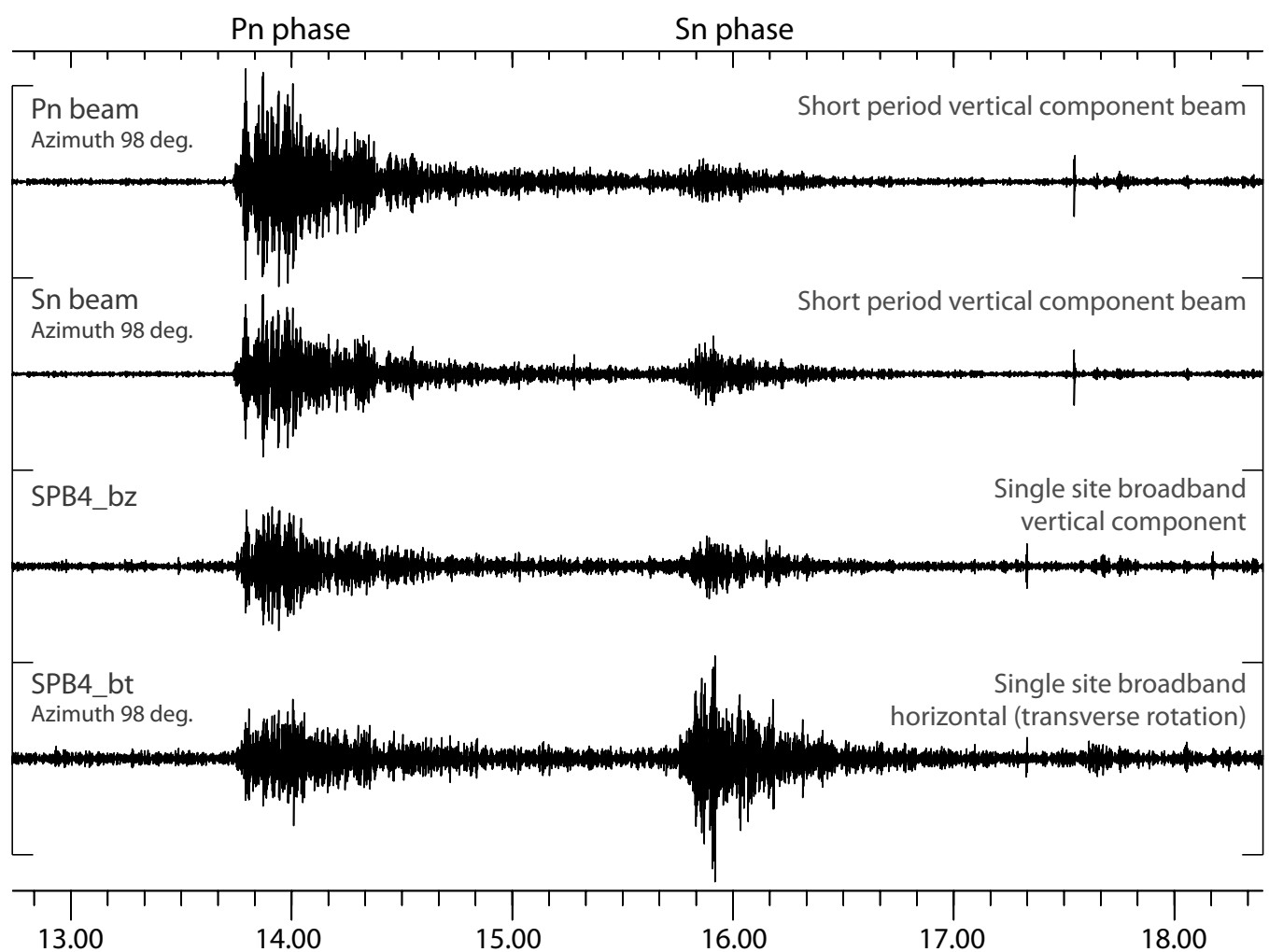

Figure 3. Pn and Sn beams for the August 16, 1997, Kara Sea event (event E in Table 1) together with the vertical and transverse rotation traces on the SPB4 broadband 3-component instrument. The time axis displays minutes after 1997-228:02.00. All waveforms filtered 4-8 Hz. 

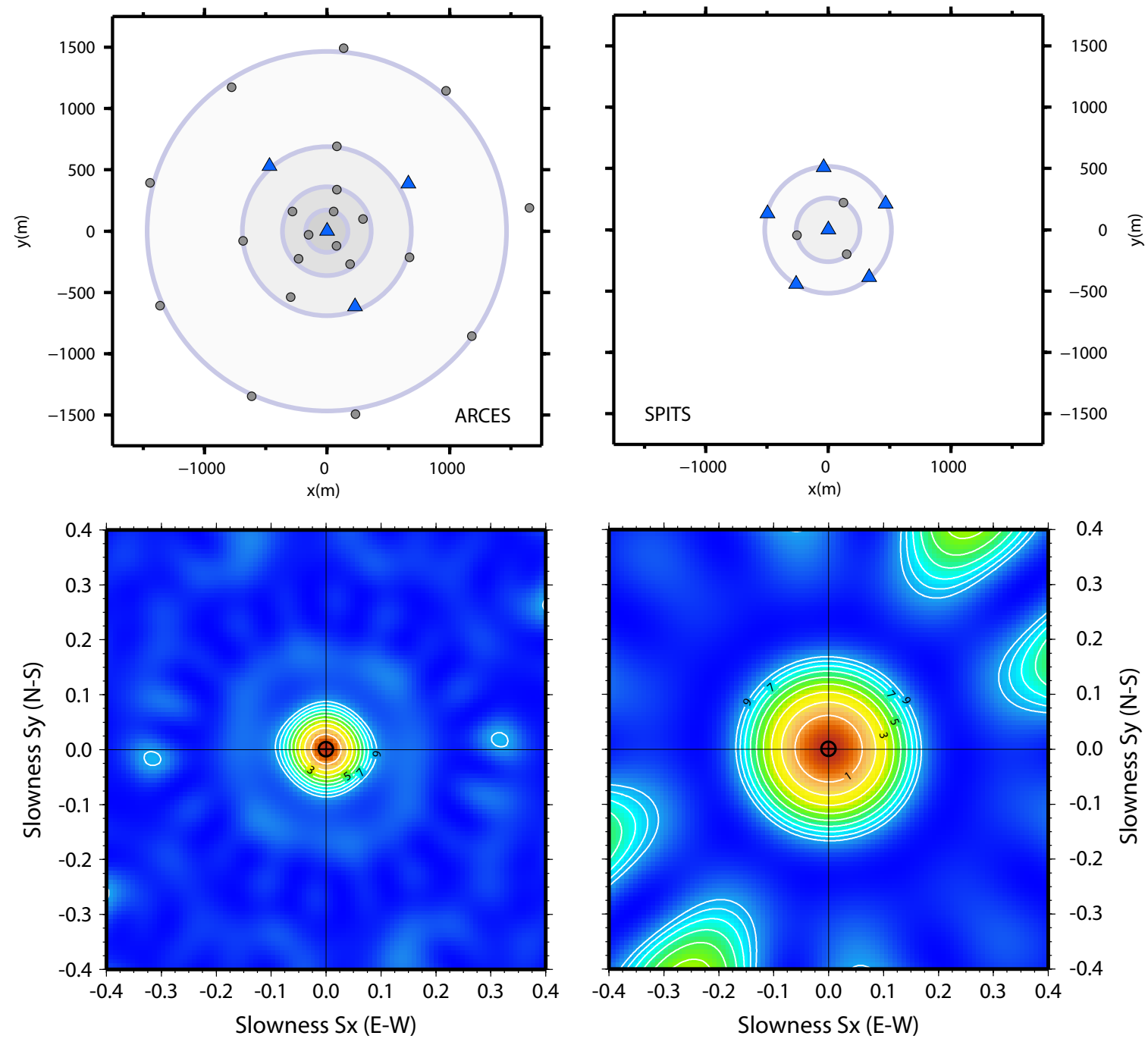

Figure 4. Configuration of ARCES (above left) and SPITS (above right) following the upgrade of SPITS in 2004. The grey circles indicate sites with vertical-only instruments and the blue triangles indicate sites with 3-component sensors. Below the array maps are the corresponding f-k grids for zero-delayed synthetic signals at $4 \mathrm{~Hz}$. These indicate the resolution provided by the arrays for high frequency regional phases as anticipated from events in the European Arctic. 

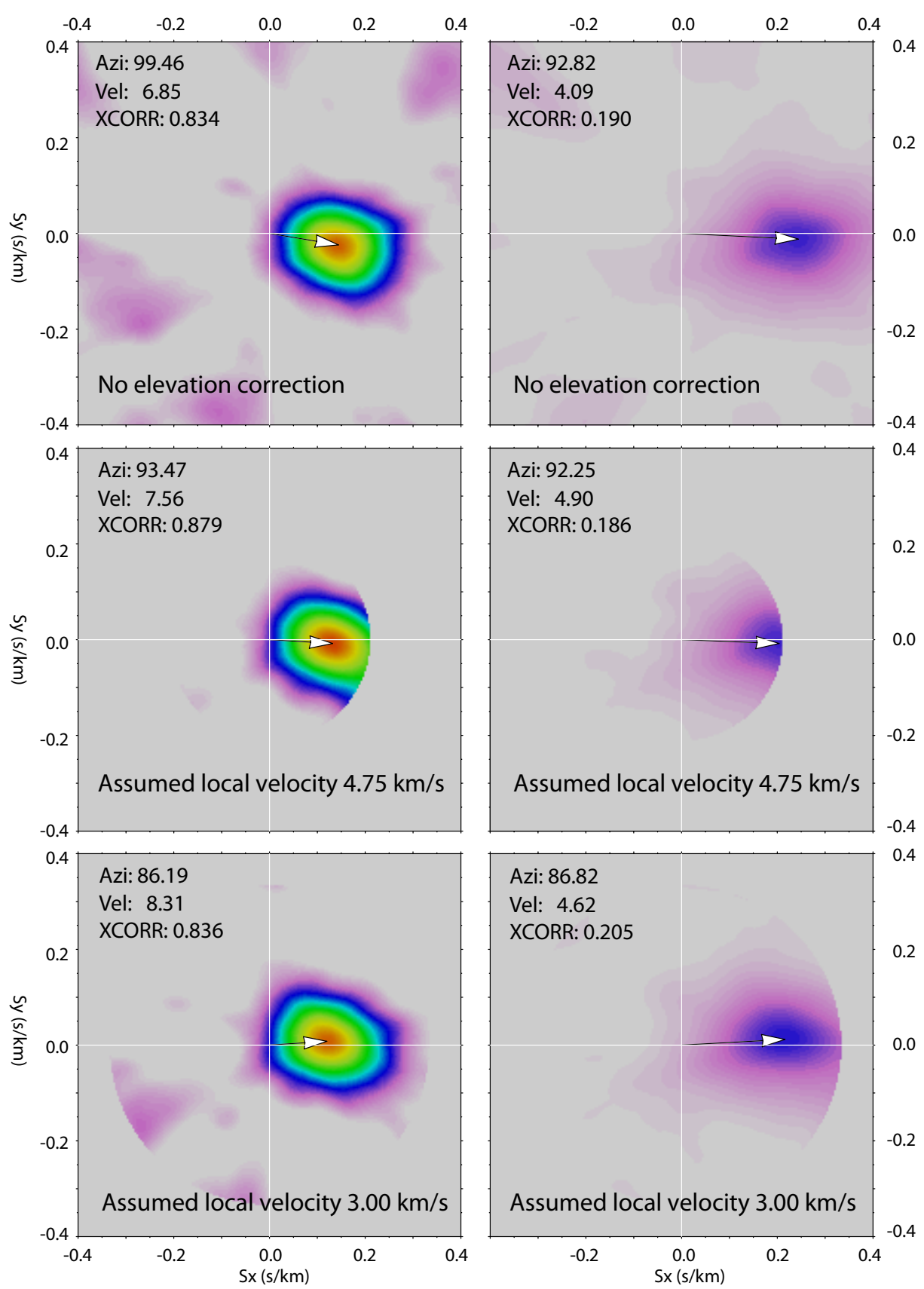

Figure 5. Slowness estimates for the Pn (left: time 2002-054:01.23.39.23) and Sn (right: time 2002-054:01.25.32.80) arrivals at SPITS for event G in Table 1 using stacking of cross-correlation traces [Frankel et al., 1991] according to time-delays specified by the horizontal slowness $s_{x}$ and $s_{y}$ together with, where indicated, a specified local velocity, $v_{\text {loc }}$. Note how the loci of valid horizontal slowness vectors is limited by the assumption of

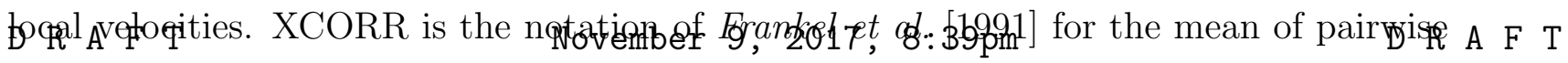
cross-correlation traces according to the specified time delays. 

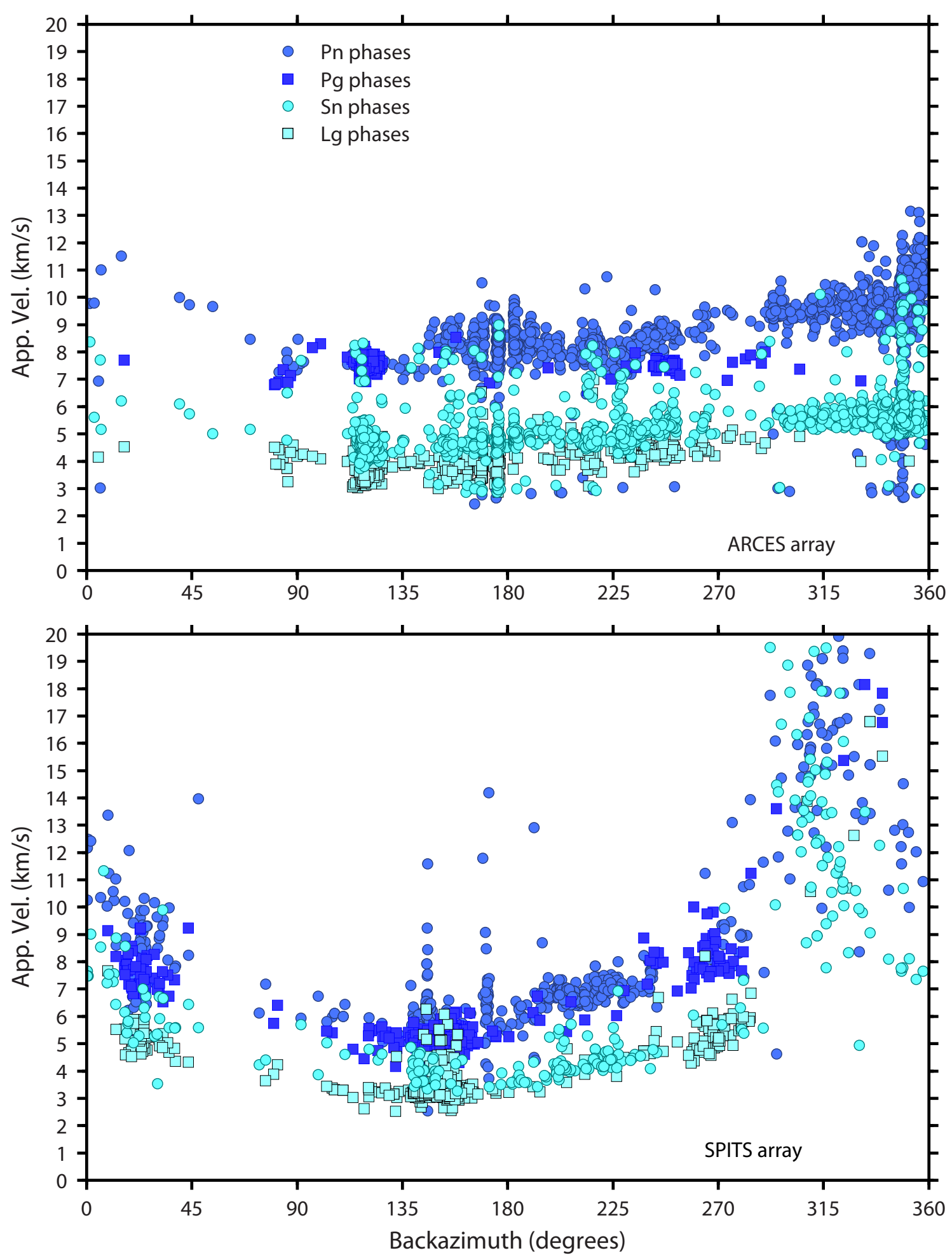

Figure 6. Apparent velocity versus backazimuth for the ARCES and SPITS arrays for the phases as indicated. All measurements are taken in fixed frequency bands in

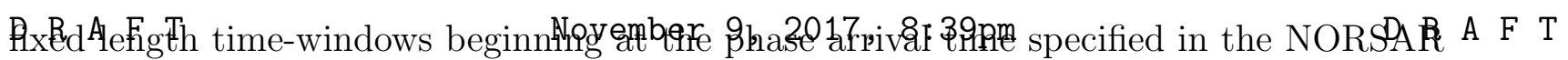
Reviewed Regional Event Bulletin. The frequency bands used are 3-8 Hz (Pn), 3-6 Hz $(\mathrm{Pg}, \mathrm{Sn})$, and 2-5 Hz (Lg). The quoted backazimuth is the geographical backazimuth to the manual location estimate from the bulletin. Location estimates in this bulletin are 


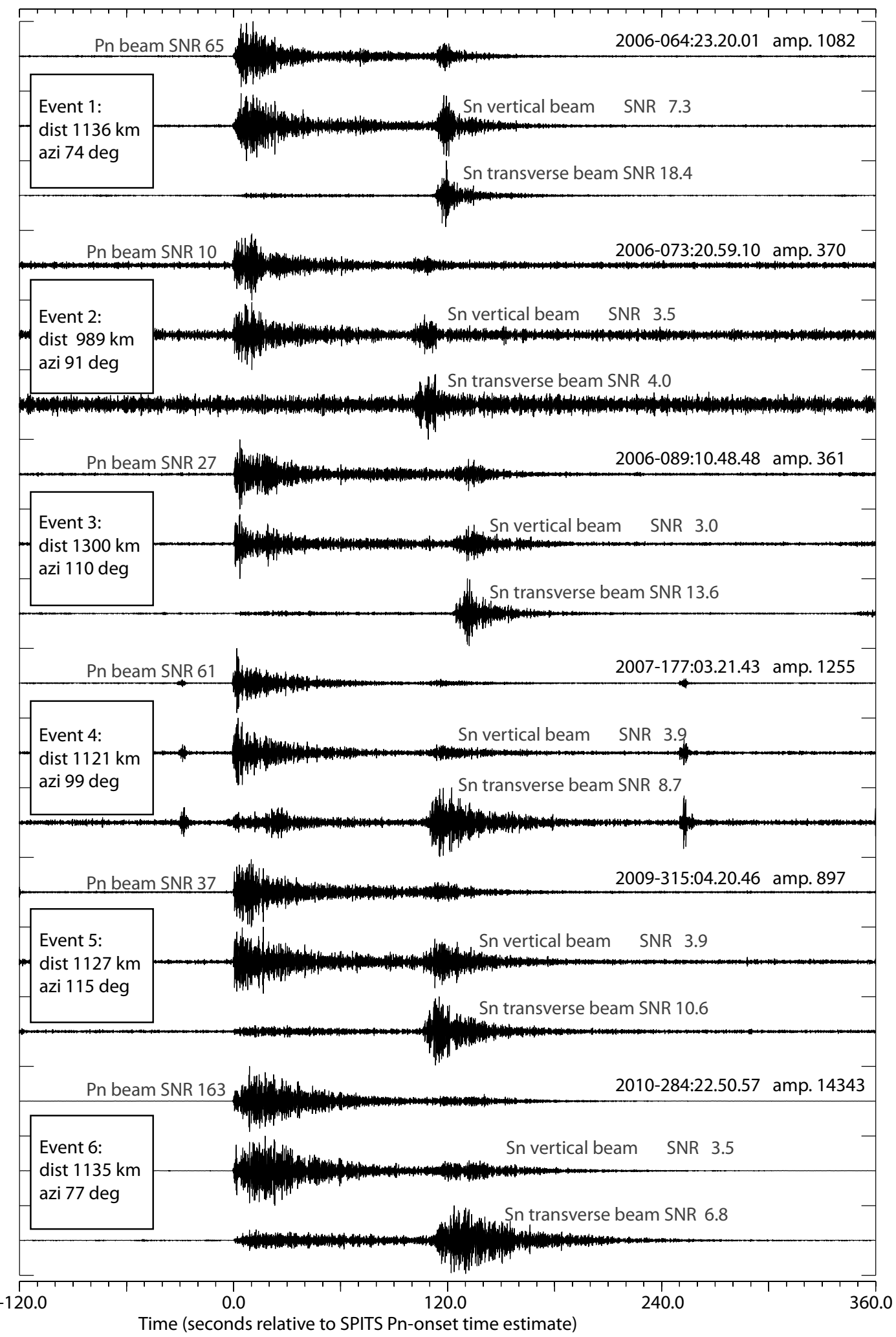

Figure 7. Beams of recent events near Novaya Zemlya. For the six events listed in Table 2, three traces are shown: Pn beam (filtered 4-8 Hz) on vertical sensors (above),

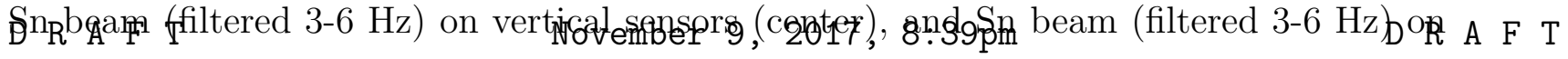
transverse rotations (below). 

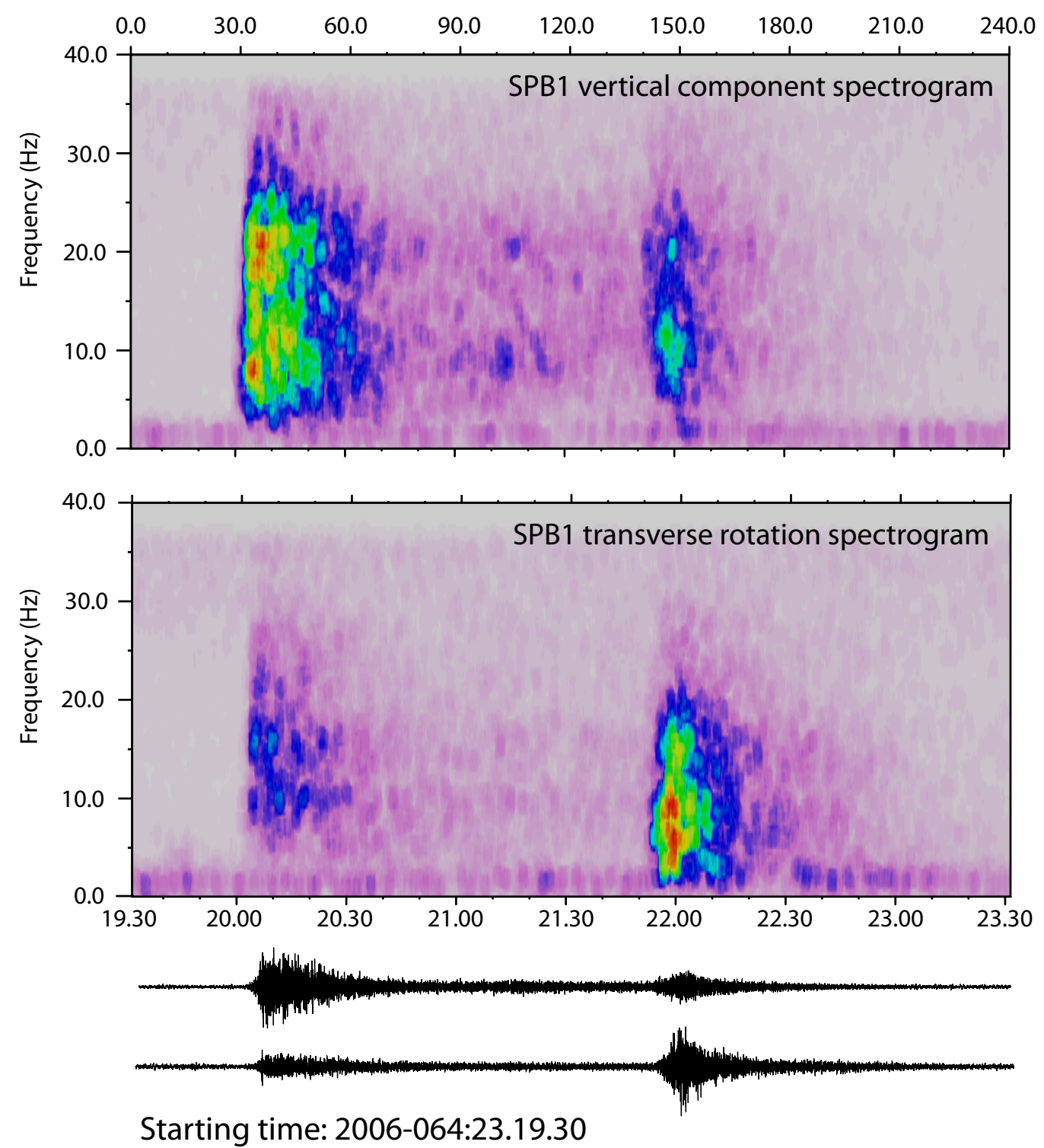

Figure 8. Spectrograms from the March 5, 2006, Novaya Zemlya event recorded at the SPB1 site. The vertical and transverse (76 degree backazimuth) seismograms were high-pass filtered above $2 \mathrm{~Hz}$ to remove the dominant low frequency energy prior to the calculation of spectra. The spectrograms were calculated using the multitaper method of Thomson [1982] on overlapping data segments of length 2.5 seconds. The color scales are adjusted automatically for each panel to display maximum contrast within each spectrogram. 


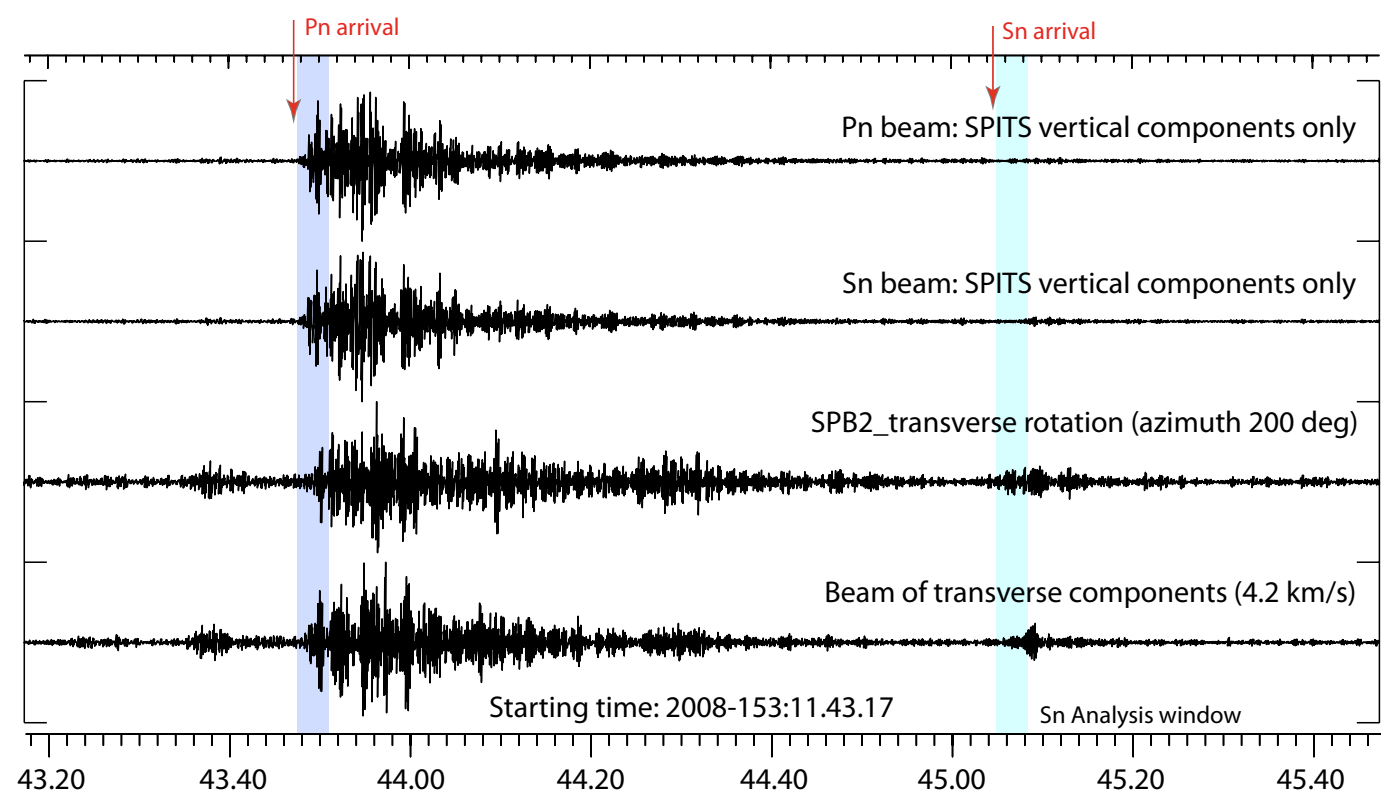

(Vertical components only, Rel. power=0.92) (Vertical components only, Rel. power=0.41) (Transverse 220 degrees, Rel. power=0.77)

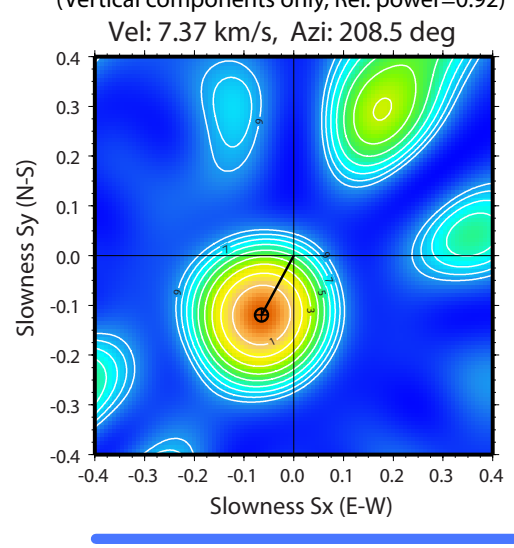

Time: $2008-153: 11.43 .47 .0+3.6 \mathrm{~s}$ Frequency band: $3.00-5.00 \mathrm{~Hz}$

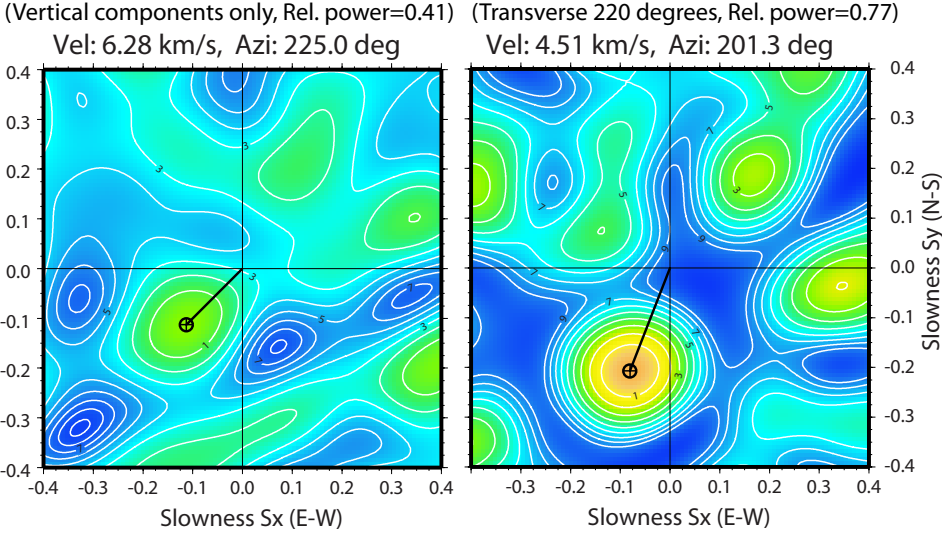

Time: 2008-153:11.45.04.9+3.6 s Frequency band: $3.00-5.00 \mathrm{~Hz}$

Figure 9. Waveforms and slowness estimates for Pn and Sn phase arrivals at SPITS for an event on Mohns Ridge at a distance of $\sim 800 \mathrm{~km}$ (reviewed event: 2008-153:11.42.05, lat $72.21^{\circ}$, lon $0.98^{\circ}$ ). All waveforms bandpass-filtered 3-5 Hz. Processing parameters for the slowness grids are provided below the respective panels. 


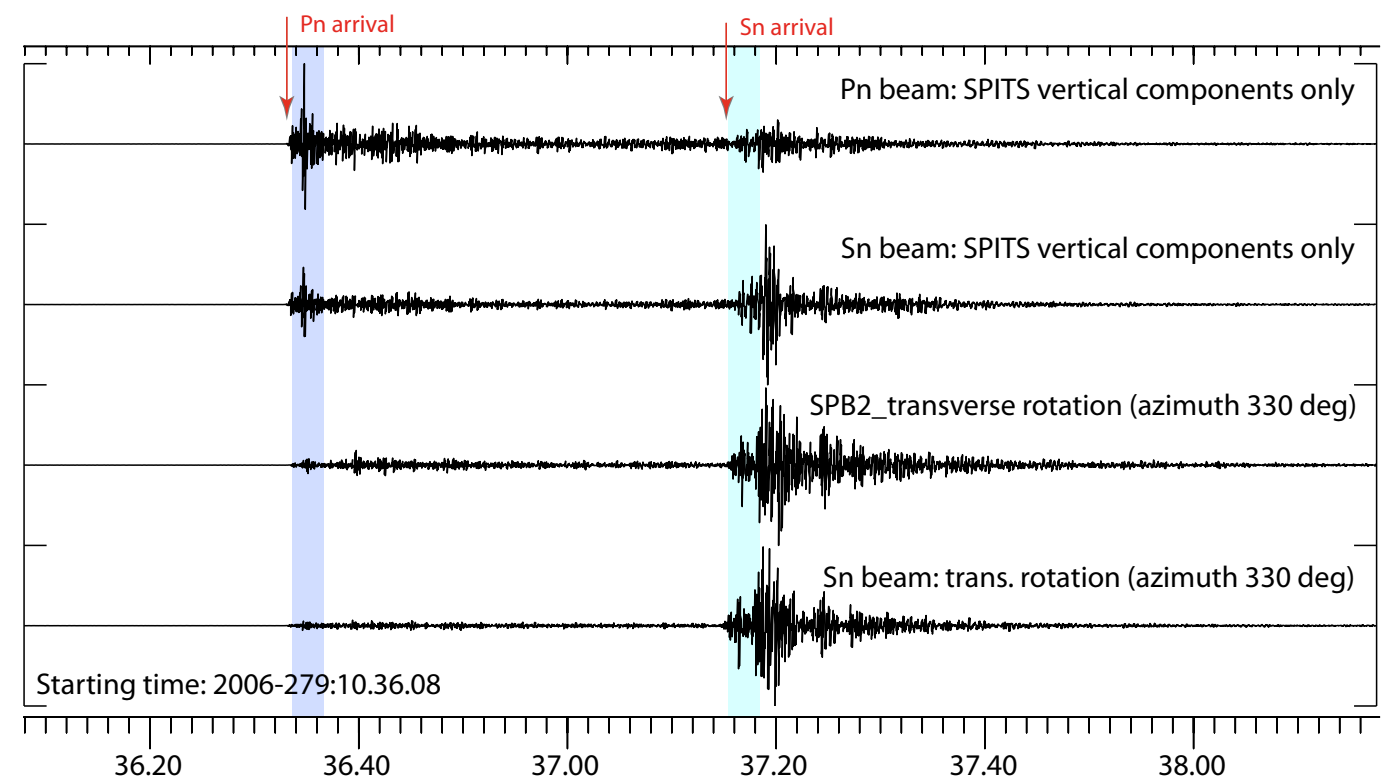

(Vertical components only, Rel. power $=0.91$ ) (Vertical components only, Rel. power $=0.43) \quad$ (Transverse 330 degrees, Rel. power $=0.84$ ) Vel: $14.2 \mathrm{~km} / \mathrm{s}$, Azi: $330.1 \mathrm{deg}$

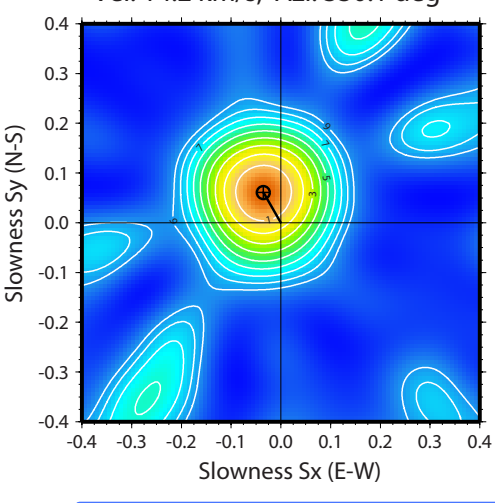

Time: 2006-279:10.36.32.8+3.6s Frequency band: $3.00-5.00 \mathrm{~Hz}$
Vel: $16.1 \mathrm{~km} / \mathrm{s}$, Azi: $358.8 \mathrm{deg} \quad$ Vel: $8.78 \mathrm{~km} / \mathrm{s}$, Azi: $325.6 \mathrm{deg}$

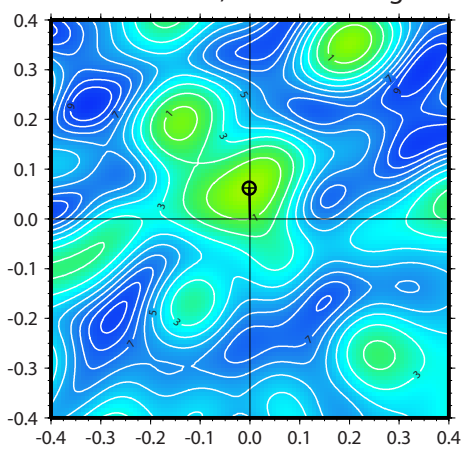

Slowness Sx (E-W)

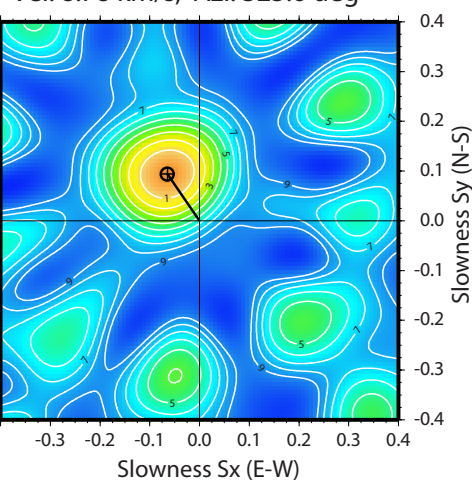

Time: 2006-279:10.37.15.9+3.6 s

Frequency band: $3.00-5.00 \mathrm{~Hz}$

Figure 10. Waveforms and slowness estimates for Pn and Sn phase arrivals at SPITS

for an event to the north west of Svalbard at a distance of $\sim 425 \mathrm{~km}$ (reviewed event: 2006279:10.35.38, lat $80.86^{\circ}$, lon $1.42^{\circ}$ ). All waveforms bandpass-filtered 3-5 Hz. Processing parameters for the slowness grids are provided below the respective panels. 

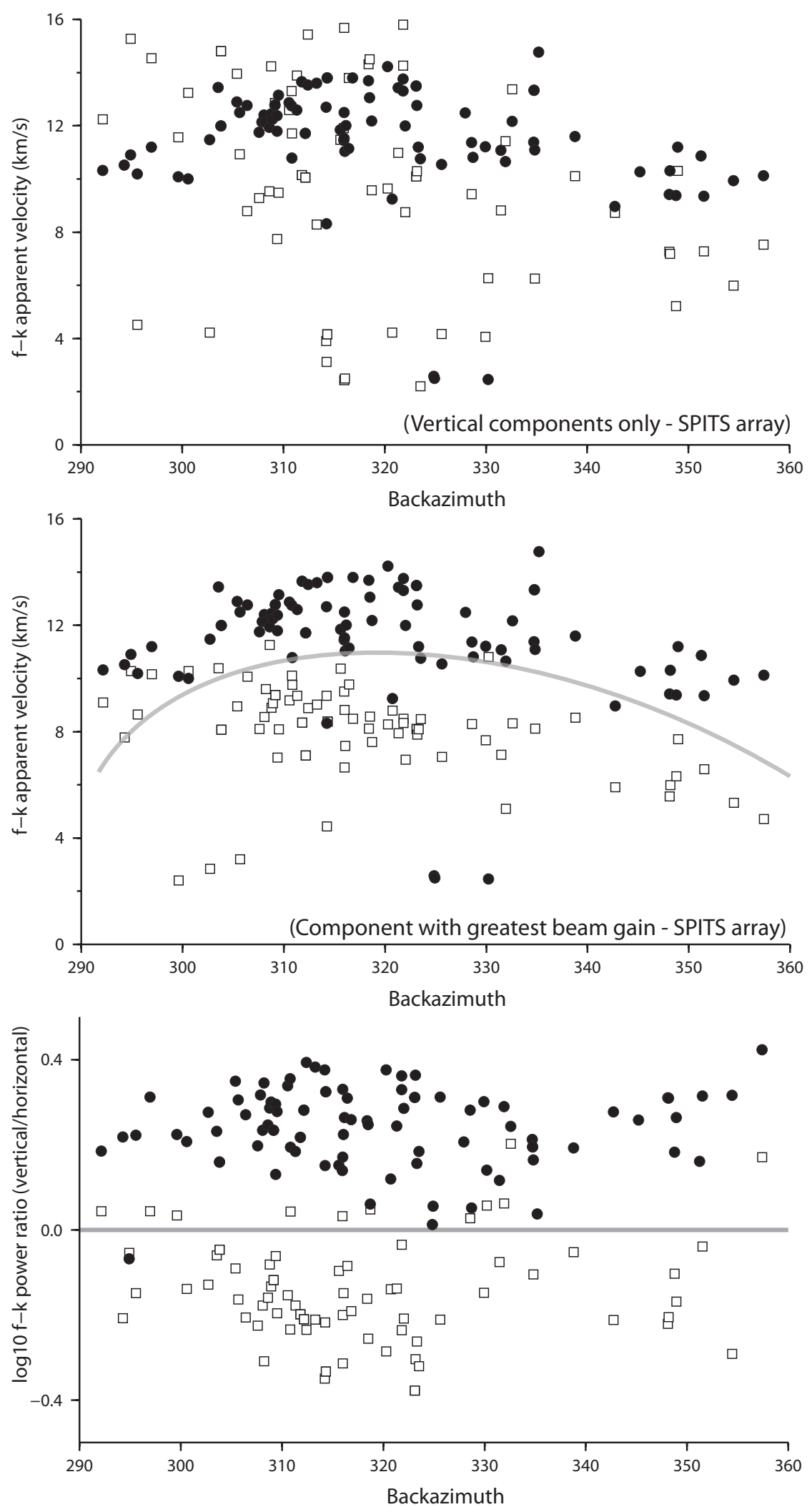

Figure 11. The separation between Pn and Sn phases using f-k analysis for events located to the north west of the SPITS array. Black circles and white squares indicate D R A F T $\quad$ November 9, 2017, 8:39pm D R A F T
slowness estimates for phases labelled Pn and Sn respectively in the NORSAR regional reviewed event bulletin. The top panel displays the apparent velocity estimate using $\mathrm{f}-\mathrm{k}$ analysis on the vertical sensors only. For each arrival, two estimates were calculated: one on the verical sensors and one on the horizontal components (transverse rotations 